\section{ADULTS WITH CAPACITY - A PRACTICAL GUIDE TO GAINING CONSENT}

\section{By Katie Crawley}

\section{Introduction}

Consent is an essential component of dentistry.

Dental students often have very good theoretical knowledge of the consent process, but they may struggle to apply this knowledge practically within dental school. ${ }^{1}$ This article therefore presents a practical guide to obtaining valid consent from adults with capacity.

\section{The basics of consent}

Dental consent encompasses a patient's implied or express permission to undergo an examination, investigation or treatment. ${ }^{2}$ Implied consent is appropriate for dental examinations, when the patient voluntarily sits in the chair and opens their mouth, but all other procedures require express consent.

The age of consent in the UK is 16 years old. However, younger children who are able to make an informed decision may give valid consent under the principle of 'Gillick competence. $^{2}$

Valid consent requires the patient's decision to be made without pressure from anyone. Adequate information about the procedure, benefits and materials risks, reasonable alternatives and consequences of inaction must be discussed. ${ }^{3}$ Finally, the patient must have capacity, meaning they can understand and use relevant information to make their decision. You should consult the Mental Capacity Act if treating an adult who is unable to consent to dental treatment. ${ }^{2}$

\section{The importance of consent}

Conducting any dental procedure without consent breaches your duty of care. This may impair your fitness to practise, result in negligence claims or criminal proceedings. ${ }^{2}$

A patient's right to take part in clinical decision making is now recognised as fundamental to good practice. ${ }^{4}$ The Montgomery ruling has aligned the legal standard for consent to this ethical principle. ${ }^{5}$ To maintain autonomy, the consent process must include a conversation about material risks. Material risks are defined as those a reasonable person in the patient's position would likely attach significance to, or those the dentist feels the patient would likely attach significance to. ${ }^{4}$ Therefore, we must get to know our patients well enough to understand the risks which are important to them.

Despite its importance, the consent process is often not the focus of dental students during clinical sessions. The development of technical skills is often prioritised. ${ }^{1}$ Understanding the theory of consent is useful, but it does not represent the whole picture. A practical guide to obtaining valid consent is therefore presented below.

\section{The consent process}

Begin the process by finding out what your patient already knows. ${ }^{1}$ This, in combination with what they want to know and what you think they need to know, will direct your conversation.

You should explain all appropriate treatment options, their likely prognosis, potential benefits and material risks. ${ }^{3}$ Then discuss the consequences of accepting or declining treatment. You should present this information in a comprehensive, but understandable, manner. This can be difficult, especially in the early years of dental school. ${ }^{1}$ Reading around relevant topics and utilising help, if required, will help to overcome any problems.

The cost of the proposed treatment, including potential future costs, must be discussed. Treatment guarantees, and exclusions, should be mentioned if relevant. ${ }^{2}$ These topics are not relevant at university, therefore they can be difficult to approach after graduation. It is helpful to understand NHS dental charges, as well as schemes which may subsidise treatment costs, to ease this transition.
You should then discuss any other relevant factors, before checking that the patient understands the information provided. Address any concerns or questions at this stage.

The patient should then be given time to consider the options before communicating their decision. This should be long enough to digest and weigh up the information provided, and is often dependent on the complexity of the proposed treatment plan. ${ }^{2}$ In an emergency situation, a patient with severe symptoms should be offered the least restrictive option. For example, relief of pain by extirpating an offending tooth, rather than extracting it, at the initial visit.

You should thoroughly document all discussions in the patient's records, in order to demonstrate valid consent. ${ }^{2}$ Written confirmation of consent may be obtained if required, although this doesn't prove consent in itself.

Consent is an ongoing process. ${ }^{3}$ Engage in further discussions and reconfirm consent during each subsequent appointment. Update patients with the progress of their care and encourage them to ask questions, ensuring they remain engaged with the consent process. ${ }^{2}$

\section{Conclusion}

Dental students may face several barriers to gaining practical experience of the consent process. This is undoubtedly compounded by the coronavirus pandemic and resultant reduction in clinical exposure. Despite these barriers, it remains important for dental students to develop their non-clinical professional skills. This practical guide to obtaining valid consent for adults with capacity, in conjunction with reflective practice and constructive feedback, may aid development of the appropriate skills under the current circumstances. ${ }^{1}$

\section{References}

1. General Dental Council. Preparedness for Practice of UK Graduates Report. 2020. Online information available at www.gdc-uk.org/docs/ default-source/research/preparedness-for-practice. pdf?sfvrsn=104075d9_12 (Accessed September 2021).

2. $\mathrm{FGDP}(\mathrm{UK})$. Clinical examination and record-keeping - good practice guidelines. 2016. Online information available at www.fgdp.org.uk/clinical-examinationrecord-keeping-standards/version-control (Accessed September 2021).

3. General Dental Council. Standards for the dental team 2013. Online information available at www.gdc-uk.org/ professionals/standards/team (Accessed October 2020).

4. D'Cruz L, Kaney H. Consent - a new era begins. $\mathrm{Br}$ Dent J 2015; 219: 57-59.

5. Montgomery (Appellant) $v$ Lanarkshire Health Board (Respondent) (Scotland) [2015] UKSC 104.

https://doi.org/10.1038/s41406-021-0267-6 